\begin{abstract}
Sight translation and written translation. A comparative analysis of causes of problems, strategies and translation errors within the PACTE translation competence model

Amparo Jiménez Ivars

University Jaume I

jimenez@trad.uji.es
\end{abstract}

This paper presents a comparative empirical exploratory study of some cognitive aspects of the oral and written translation process within the translation competence construct. This research has a twofold objective: finding some evidence of specific translation competence skills in translation tasks and comparing these data in sight translation and written translation in order to empirically check if sight translation can really be considered an interpreting modality. A sample of 22 Translation and Interpretation students after the final last year examinations was used. They performed a sight translation and a written translation of the same text and answered retrospective questionnaires regarding causes of problems, and strategies used to solve them. Errors were assessed afterwards using three basic criteria: non-sens, faux sens and contresens. Results showed quantitative and qualitative differences in number of problems, their causes and strategies used. It also revealed more errors in sight translation. Qualitative results have been successfully incorporated to the PACTE translation competence model showing that empirical data corroborate the theoretical model. Specific results also show that psycho-physiological components are more relevant in sight translation, as it is the case in interpreting modalities, and knowledge about translation referring to reexpression, deverbalization, master of translation units is more relevant in written translation.

KEYWORDS: sight translation, written translation, translation competence, translation strategies

\title{
BIOSKETCH
}

Dr. Amparo Jiménez Ivars is a lecturer in Translation and Interpreting at the University Jaume I of Castellón (Spain) where she teaches conference interpreting. Her research interests are in the didactics area, interpreting aptitudes and new technologies applied to interpreting training. She has published a number of papers in these fields favouring the experimental approach. 
Sight translation and written translation. A comparative analysis of causes of problems, strategies and translation errors within the PACTE translation competence model

Amparo Jiménez Ivars University Jaume I jimenez@trad.uji.es

This paper presents a comparative empirical exploratory study of some cognitive aspects of the oral and written translation process within the translation competence construct. This research has a twofold objective: finding some evidence of specific translation competence skills in translation tasks and comparing these data in sight translation and written translation in order to empirically check if sight translation can be considered an interpreting modality. Sight translation, when performed without previous reading, is considered by some authors to be closer to interpreting than to written translation both because of the immediacy that imposes strict time restrictions and the oral nature of the task (Curvers et al., 1986; Martin, 1993; Viezzi, 1990; Jiménez Ivars, 2001; Agrifolio, 2003; Agrifolio, 2004). This study may shade some light on the nature of the sight translation modality.

The study of the translation process is closely connected with the study of translation strategies, that is to say, the answer to what goes on in the translator mind is connected with what the translator does to solve problems (Hurtado, 2001). In order to access this process we aimed at identifying specific causes of translation problems, strategies applied to solve them and the number and types of major errors produced.

Translation problems and strategies as a means to getting insights into the translation process have been dealt with by several authors both from the written and oral translation perspective. Dollerup 1982, Krings 1986, 1987; Königs 1987; Tirkkonen-Condit 1989; Lörscher 1991, 1992, 1996; Mondhal and Jensen 1996; Kussmaul 1997; González, Rodríguez and Scott-Tennent 2000; Hansen 1999 apud Orozco and Hurtado Albir, 2002 focused on written translation whereas and Gile, 1985; 1995; 2002, Kalina, 1992; 1994; 2000; Sunnari, 1995, Gran, 1998, Ivanova, 2000, Abuin González, 2004 apud Abuin González, 2007 focused on interpreting.

We are aware that the concept of strategy has been widely discussed in many disciplines including translation studies but an analysis of the epistemological nature of strategy exceeds the purpose of this work. For this reason a practical definition that fits our purpose will suffice. We shall follow Hurtado's approach (2001) based on 
translation studies, cognitive psychology and second language teaching. She defines strategies as the individual procedures, conscious and unconscious, verbal and nonverbal, internal and external used to solve the problems encountered during the translation process. Consequently, the concept of strategy goes inextricably linked to the concept of problem. Therefore, in order to identify translation strategies we shall focus first on translation problems, and more specifically, on the self-perceived causes of these problems since strategies are individual procedures to solve them. Problem solving is an indication of competence, meaning that in order to solve a particular problem a strategy directly related to the problem must be activated.

\section{Translation competente}

The PACTE research group (2003:57-59) defines translation competence as the ability to carry out the transfer process from the source text to the production of the target text in function of the receptor's needs and the purpose of the translation. The PACTE model of translation competence includes the following sub-competencies.

1. Bilingual sub-competence. Procedural knowledge needed to communicate in two languages; it includes the ability to control language interferences. Translation problems within this category are socio-linguistic, pragmatic, textual, grammatical and lexical. Some of the strategies required to solve them include differentiating and identifying socio-linguistic conventions, textual structures and language registers.

2. Extralinguistic sub-competence. It refers to the declarative knowledge about the world in general and special areas. It covers bicultural, encyclopaedic and subject knowledge. An adequate use of the cognitive capacity to manage knowledge and the proper use of documentation sources are the means to solve these translation problems.

3. Knowledge about translation. Declarative knowledge, both implicit and explicit, about what translation is and what the translator is expected to do.. It includes knowledge about the functioning of translation: translation units, processes, methods, procedures and types of translation problems. Lack of this knowledge presents a wide variety of problems: deverbalization, reexpresión, choosing a translation method, etc. In sight translation change of mode (from written to oral), time pressure and difficulties in deviating from the source text form are the most common problems.

4. Instrumental sub-competence. Procedural knowledge related to professional practice: management of documentation sources, ICT’s applied to translation, labour market, professional practice. Problems derive from the particular translation assignment. 
5. Psycho-physiological components. PACTE (ibid) considers these to be part of expert knowledge. They include different types of cognitive and attitudinal components and psycho-motor mechanisms. Among them we find cognitive components such as memory, perception, attention span, creativity, logical reasoning capacity, analysis, synthesis and emotion; attitudinal aspects such as intellectual curiosity, motivation, perseverance, rigour, discipline, critical spirit, creativity, as well as confidence in one's own abilities (self-efficacy) and knowledge about personal limitations. In interpreting many specific problems arise from time pressure and public performance. Many of the mentioned components become crucial

6. Strategic sub-competence. It intervenes by planning the translation process, assessing it, activating the different sub-competencies. The strategic sub-competence compensates for deficiencies in the other sub-competencies, identifies translation problems and applies procedures to solve them. It is therefore the most important subcompetence within the PACTE model. However, they consider only three subcompetencies specific to translation: the strategic, the instrumental and knowledge about translation.

\section{Research design}

The study was addressed from two perspectives: 1) translation as a process with the identification of causes of translation problems and strategies applied to solve them 2) translation as a product with the identification of three types of major content errors. The main objective of this work is to describe and compare specific aspects of translation competence with data provided from a sight translation (ST henceforth) and a written translation (WT henceforth) task. In order to achieve this objective we aimed at identifying the following items in each translation modality: 1) Self-perceived causes of the problems. 2) How each particular problem is perceived to have been subjectively solved 3) Major translation errors. Data referring to the translation process were collected by means of a retrospective questionnaire ${ }^{1}$ just after the performance of each task. For the translation product three assessment parameters were applied (infra).

Given the fact that sight translation is subject to time constraints, the process goes through a change of mode and that the presence of the written text while

\footnotetext{
${ }^{1}$ Method used in interpreting studies by several researchers (Kalina, 2000; Ivanova, 2000; Mead, 2000; Vik-Touvinen, 2000; Abuin, 2007).
} 
translating aloud may interfere with the target language, it can be considered that written translation and sight translation are different translation modes and therefore they will present differences in the process and in the product. Four hypotheses were posed: We assume that the translation process differs when performed at first sight or when it is written, therefore translation problems must be qualitative and quantitative different in each modality (hypothesis 1). Causes of these problems must be different (hypothesis 2). Strategies applied to solve problems will be different (hypothesis 3). Due to the constraints mentioned above the process of sight translation must demand more cognitive resources than that of written translation, therefore the number of major translation errors in sight translation will be greater (hypothesis 4).

The sample consisted of a homogeneous group of 22 last year Translation and Interpreting students of the University Jaume I (Spain) a few days before graduating. They had all taken a 30 hour course in Sight Translation English-Spanish. Overall they had taken 220 hours in interpreting and around 400 hours in translation with the language combination English-Spanish. None of them had professional experience.

The independent variable refers to the translation modality. The dependent variables referred to the translation process are the following: number of self-perceived translation problems ${ }^{2}$, self-perceived causes of these problems and strategies used to solve them. The dependent variables referred to the translation product are three major translation error types.

The measuring instruments of the dependent variables are a retrospective questionnaire to identify translation problems, causes and strategies used and three assessment criteria for translation errors: non-sens (lack of sense), faux sens (substantial change of meaning of source text) and changes to the contrary (contresens). The same questionnaire and assessment criteria were used for both oral and written translation tasks.

Materials: a non specialized text of 224 words in English (see Appendix). The text contains indicators of linguistic, extra-linguistic, instrumental and psychophysiological problems.

An initial and a final questionnaire complemented the study to rule out hidden variables (age, gender, training, experience, language levels, mother tongue, motivation, etc.). The procedure was applied as follows: 1. Subjects filled out the initial

\footnotetext{
${ }^{2}$ The specific translation problems do not concern this study and therefore have not been reported.
} 
questionnaire. 2. They were given the text and proceeded to immediately record their sight translation into Spanish in an interpreting booth without time to read it beforehand. 3. Subjects filled out the retrospective questionnaire (see Appendix). 4. Immediately after subjects translated the same text in written form with the aid of monolingual and bilingual dictionaries. No time limit was set for this task. 5. Subjects filled out again the same retrospective questionnaire as before. 6. They filled out the final questionnaire.

\section{Data análisis}

1) Problematic translation elements. "What specific problems did you come across during the sight translation performance?

The number of problematic elements was 26 although their identification is not relevant for the purpose of this study only concerned with cognitive aspects, namely, the causes of translation problems. 24 were found in ST and 15 in WT (13 of them were common to both modalities). Their frequency almost doubled (102 in ST vs. 59 in WT). The frequency of detected problems in both modes was 161 whereas the frequency of solutions (regardless of their adequacy) was 133. 17.4 per cent of the declared problems were not credited with any solution.

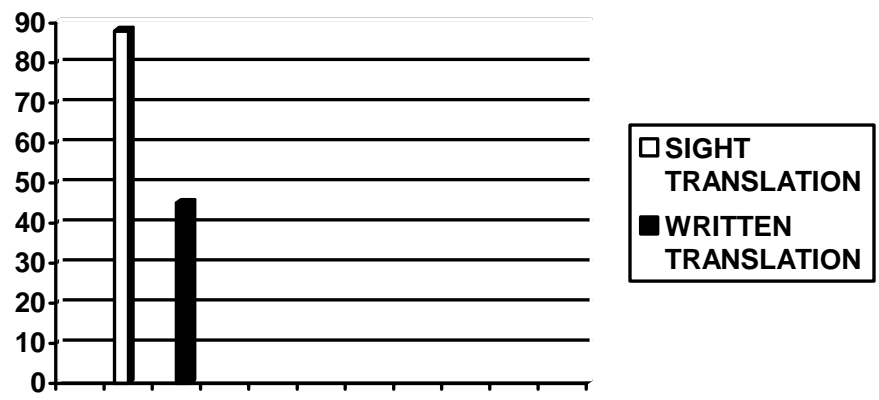

Fig. 1: Frequency of self-perceived problems in both modalities.

2. Subjective causes of problems. What were the causes of these problems? State them whether you were able to solve them or not. You don't have to fill in every blank but add elements if necessary.” 
The frequency of self-perceived causes of translation problems amounts to 102 in sight translation and 59 in WT. Tables 1 and 2 present the self-perceived causes of problems. A total number of eight different causes have been detected. Five in WT and six in ST (three of them were shared).

\begin{tabular}{|l|l|}
\hline $\begin{array}{l}\text { Linguistic understanding } \\
\text { The translation equivalent did not } \\
\text { spring to mind }\end{array}$ & 23 \\
\hline $\begin{array}{l}\text { I did not read ahead enough } \\
\text { Conceptual understanding }\end{array}$ & 21 \\
\hline I did not deviate from source text & 15 \\
\hline Misreading & 12 \\
\hline
\end{tabular}

Table 1. Causes of translation problems in ST

\begin{tabular}{|l|l|}
\hline Linguistic understanding & 18 \\
\hline Documentation problems & 15 \\
\hline Expression problems & 12 \\
\hline Conceptual understanding & 9 \\
\hline $\begin{array}{l}\text { I could not deviate from the source text } \\
\text { form }\end{array}$ & 4 \\
\hline
\end{tabular}

Table 2. Causes of translation problems in WT

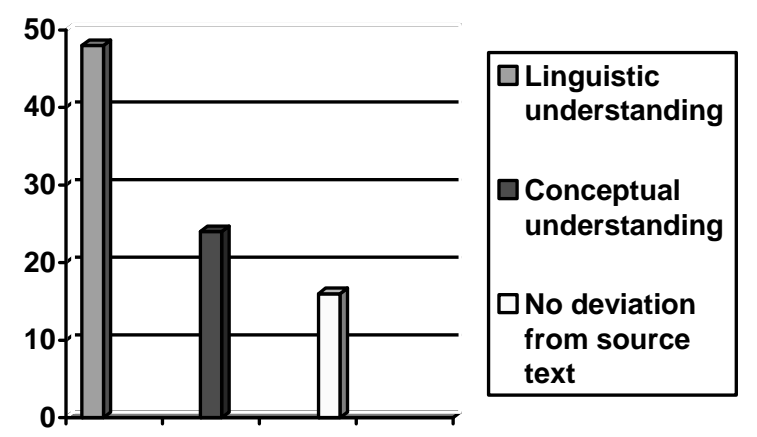


Fig. 2 Frequency of shared causes of problems
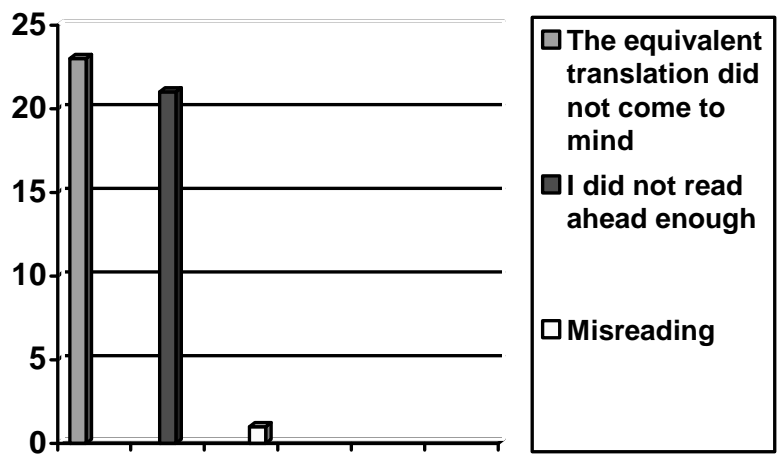

Fig. 3: Frequency of specific causes of problems in ST
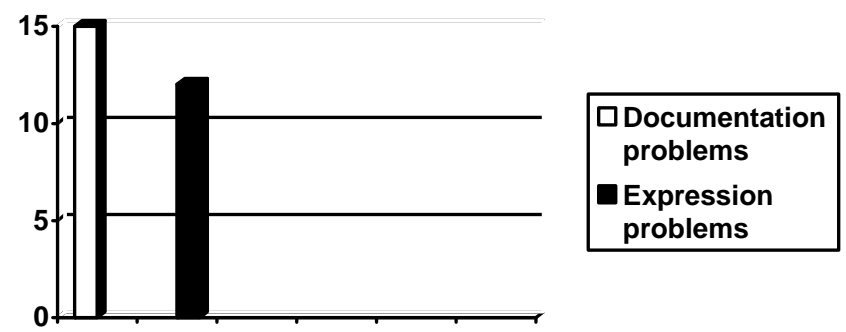

Fig.4: Frequency of specific causes of problems in WT

3. Problem solving strategies. "State what you did to solve each of the above mentioned problems. 1 stands for problem 1; 2 stands for problem 2, etc”

Table 3 presents the total number of strategies identified by the sample. Answers that did not entail any solving procedure (i.e. "I did it wrongly”) were removed.

\begin{tabular}{lllll} 
& STRATEGY & ST & WT & $\begin{array}{l}\text { TOTAL } \\
\text { (Frequency) }\end{array}$ \\
1 & Selecting the main idea & 13 & 11 & 24 \\
2 & Omitting information & 16 & 2 & 18 \\
3 & Avoiding the same word order & 5 & 6 & 11 \\
4 & Avoiding the automatic translation & 4 & 2 & 6 \\
& equivalent & & & \\
\hline 5 & Word for word translation & 5 & - & 5 \\
\hline 6 & Invention & 4 & - & 5 \\
\hline
\end{tabular}




\begin{tabular}{lllll}
\hline 7 & Reading ahead & 4 & - & 4 \\
\hline 8 & Consulting dictionaries & - & 4 & 4 \\
\hline 9 & Infering from the context & 1 & 3 & 4 \\
\hline 10 & Restarting textual units. & 3 & - & 3 \\
\hline 11 & Saying whatever first springs to mind & 2 & - & 2 \\
\hline 12 & Paraphrasing & 1 & 1 & 2 \\
\hline 13 & Rereading sentences & 2 & - & 2 \\
\hline 14 & Translating aloud & - & 2 & 2 \\
\hline 15 & Reasoning & 1 & 1 & 2 \\
& FREQUENCY TOTAL & $\mathbf{6 1}$ & $\mathbf{3 3}$ & $\mathbf{9 4}$
\end{tabular}

Table 3. Problem solving strategies for both modalities. In italics and dark shading strategies used exclusively in ST. In bold and light grey shading strategies used exclusively in WT. In regular font and white shading shared strategies.

\section{OMISSION}

Selecting the main idea

Avoiding the same Word order

Word for word translation

Avoiding the automatic equivalent

translation

Inventing

Reading ahead

Restarting

Saying whatever springs to mind

Rereading

Infering from the context

Paraphrasing

Reasoning

Table 4: Frequency of strategies used in ST

SELECTING THE MAIN IDEA

Avoiding the same word order

Consulting dictionaries

Infering from the context

Omission

Avoiding the automatic equivalent

Translating aloud

Paraphrasing

Reasoning

Inventing

Table 5: Frequency of strategies used in WT 

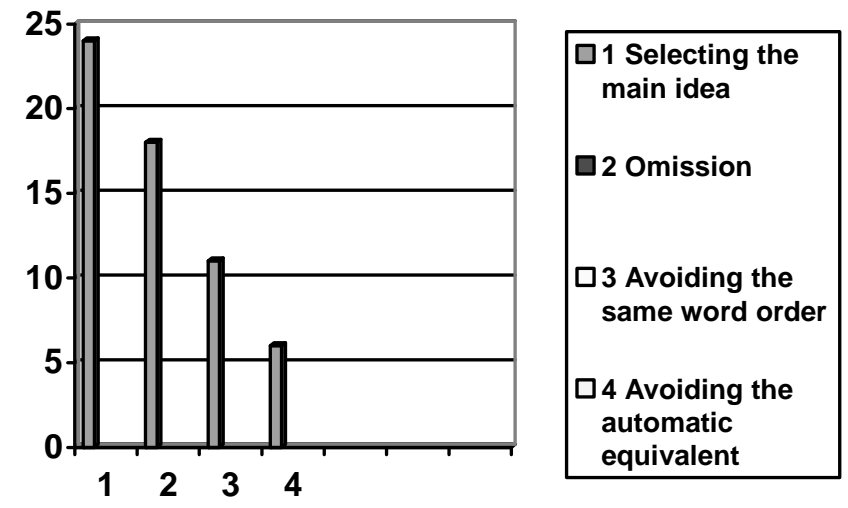

Fig. 5 Frequency of shared strategies

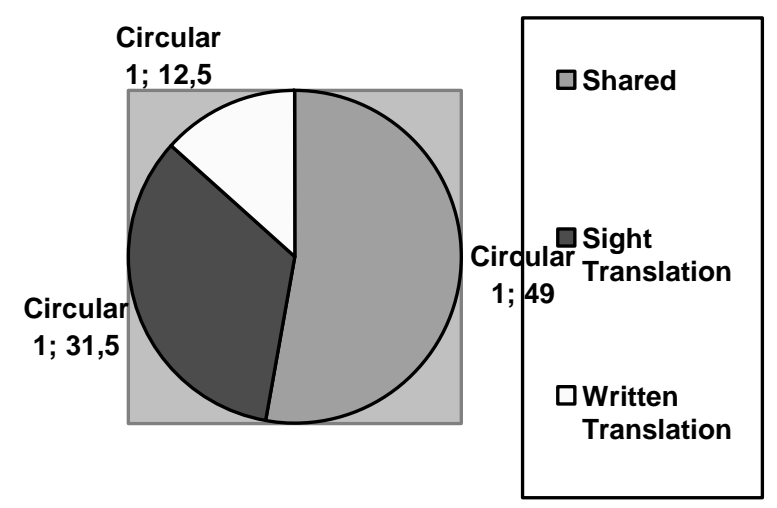

Fig. 6: Percentage of specific strategies used in each modality

2. 4. Frequency of problem solving. "How do you assess each of your solutions. Use the following criteria: 0: unacceptable solution. 1: Partially acceptable solution. 2. Acceptable solution”

Self-perception of acceptable or partially acceptable solved problems is also reversed: 36.37 percent vs. 75.55 percent. 


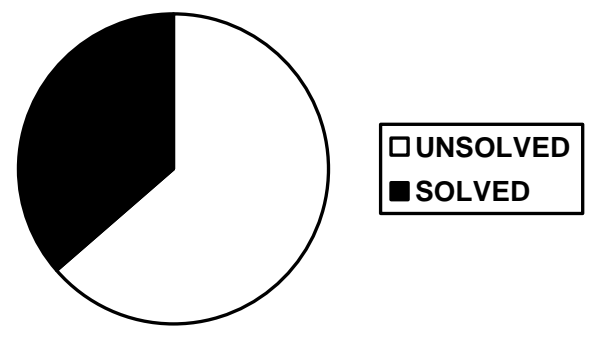

Fig. 7 Percentage of solved problems in sight translation

\section{Errors}

In order to measure the number of errors the ST output was transcribed. For the purpose of this study prosodic features (including pauses) were not taken into account and were not transcribed. After identifying the three major type errors in each modality (Nonsense; Contresens and Faux Sense) it was found that the frequency of contresense and faux sense was not substantially different in each mode. The exception was the non-sen as can be seen in figure 9 .

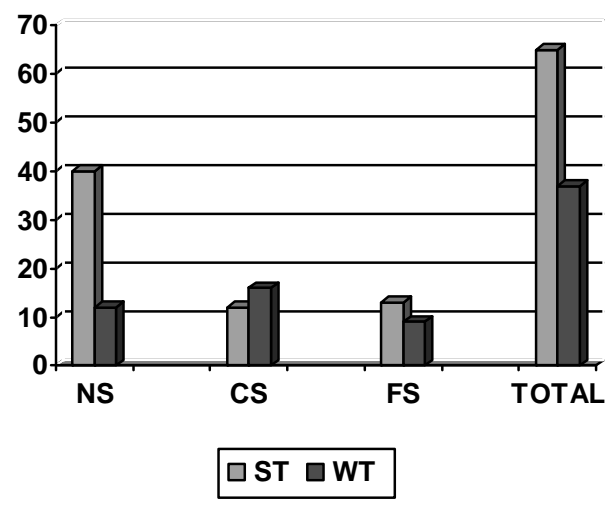

Fig. 9: Errors made in sight translation and in written translation (NS: Non-sens, CS : contresens, FS: faux sens)

\section{Discussion}

As pointed out above, this paper aimed at finding empirical evidence regarding specific causes of translation problems and strategies to fit within the framework of the PACTE translation competency model (supra). A high intersubject variability is present 
involving causes and strategies used to solve any particular problem. That is, any particular translation problem has been found to respond to different causes for different subjects.

The most frequent cause for problems was a deficiency in linguistic understanding. A skill of the bilingual sub-competence. The sample considered this as the major cause for translation problems in consistence with Lörscher experimental results (1991). Answers like "The equivalent I was looking for did not spring up to mind" "I haven’t read ahead enough" or "I have misread a word" have a cognitive component. The latter two are more specifically associated to fast and efficient reading. They are part of the psycho-physiological components. Such causes of problems have not surfaced in written translation. Finding hard to deviate from the source text form and having problems to reshape the target text belong to the translation knowledge subcompetence. Documentation problems are subsumed under the professional/instrumental sub-competences. Difficulties to understand ideas, provided they are not caused by a lack of linguistic knowledge, respond to a deficiency in the extra-linguistic sub-competence.

In sight translation the principal cause of translation problems (see table 1) was a deficient linguistic understanding of the source text. Secondly, difficulties in finding promptly the translation equivalent. This is a typical interpreting skill associated to quick lexical access. Not being able to read ahead is the third reported cause. As mentioned before, it is cognitive in nature and connected to fast reading. It is an activity that must precede the translation process (Weber, 1990). Next comes difficulties to understand ideas and finally misreading. The latter is specific of ST.

In written translation the main cause of problems was also linguistic understanding of the source text (see table 2) although the frequency dropped a 50 per cent with respect to sight translation. Problems with the documentation sources come next, these problems represent a modality-bound feature that cannot be taken into account in sight translation. The third cause, difficulties in reshaping the output was not mentioned in ST. It seems that there is more awareness about target language adequacy in WT than in ST. This could be explained by the fact that instant response and communicability are priorities in ST, typical interpreting features. In the light of the answers, language issues become less relevant in WT. Finally, three out of the six 
detected causes in ST were modality specific and can be subsumed under the psychophysiological components of the translation competence. In written translation causes are more diverse: linguistic (understanding, re-expression, problems to deviate from the source text form), professional/instrumental (documentation) and extra-linguistic (understanding of ideas).

According to the results, we can tentatively conclude that translation problems are quantitatively different in each modality in consistence with hypothesis 1 . Out of the six translation causes of problems disclosed, three are specific of ST, two are specific of WT and one is shared, partially corroborating hypothesis 2. Five out of the 15 strategies applied to solve problems are specific of ST, two are specific of WT and eight are shared, partly in consistence with hypothesis 3 . There is also a quantitative difference in relation to the frequency of strategies applied: 61 in ST vs. 33 in WT. The number of strategies is also lower in WT: 13 different strategies in ST, five of which are specific versus ten different in WT, two of them specific. The sample did not identify strategies used in WT as readily as in ST. This could perhaps mean that the sample's skills in written translation process had become more automatic than the interpreting skills and awareness of strategies did not surface as readily. Given that external aid is not possible in ST data show how subjects have had to resort to internal abilities in order to perform the task. The number of translation errors found also support hypothesis 4 (37 errors in written translation vs. 65 in sight translation). The overall results of this study partially support the four hypotheses.

Figure 10 presents the self-perceived causes of translation problems adapted to the PACTE translation competence model (2003:60). 


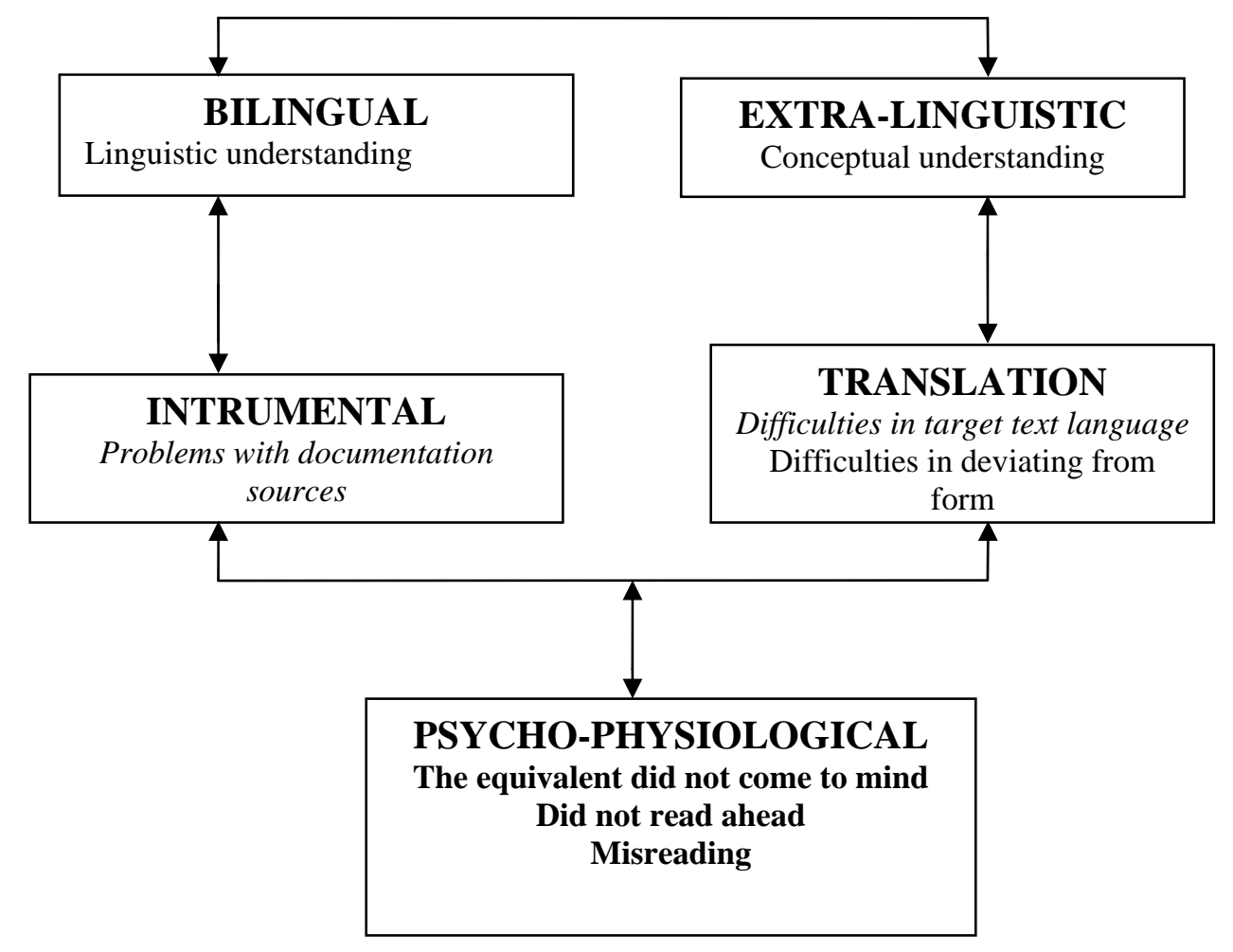

Fig.10. Causes of problems in both modalities: in regular font shared causes, in italics specific causes for written translation, in bold specific causes for sight translation.

As to translation strategies, it must be pointed out that the high number of errors reveals that the strategies used were not the most adequate or were not correctly applied. Nevertheless, their identification has helped to shed light on the translation process. The most widely used strategy in both modalities was selecting the main idea. It is a cognitive skill that presupposes analysis, both skills stem from the psycho-physiological components of the translation competence. The second most widely used strategy, omission, was mostly applied in ST. Omitting information is a usual feature of interpreting associated to the strategic sub-competence to make up for deficiencies, it is a usual interpreting “emergency strategy” (Riccardi, 2005).

In WT omission as a problem solving strategy does not constitute a common or even accepted strategy. The third strategy, avoiding to reproduce the same word order of the source text and the fourth strategy, avoiding the automatic equivalent are associated to the knowledge about translation sub-competence. The former was more widely applied in ST perhaps due to a higher awareness of faux amis risks. The fifth 
strategy, invention, came up four times in ST and is connected with rapid decision making. Next, inferring from the context received three answers in WT and one in ST. This shows that, like in other interpreting modes, time constrains and the linearity of the task hinders the macroprocessing skills. Inferring from the context, when context is taken in its broadest sense, becomes an extralinguistic sub-competence. Finally, reasoning and paraphrasing with one answer in each modality. The former associated to the psycho-physiological components and the latter to the bilingual sub-competence.

As to the six specific strategies of ST the most extensively used was word for word translation. A plausible explanation for this may be that the context hardly played any role during the translation process according to the answers (there was just one mention of it). This may have resulted in a greater tendency to translate linearly responding to an emergency strategy of the translation sub-competence. The second specific strategy, reading ahead, belongs to the strategic sub-competence as a means to manage the complex task of reading, mentally translating and re-expressing simultaneously. It involves fast and efficient reading skills to gain time during the translation process. The third strategy, re-starting the text, is an emergency strategy aimed at improving the target text to compensate for any errors or to avoid making them. Next, saying whatever comes first to mind is a specific cognitive resource included in the psycho-physiological components associated to quick lexical access. Finally, re-reading the sentence can be included in the strategic sub-competence.

It goes without saying that the specific strategies of WT -consulting dictionaries and translating aloud- could not be used in ST for obvious reasons. The former is not allowed and the latter is what sight translation is all about. In WT both the number of strategies -10 vs. 13 in ST (table 5) - and the frequency -33 vs. 61 in ST- were lower.

The strategies discussed here are presented within the PACTE translation competence model (ibid). 


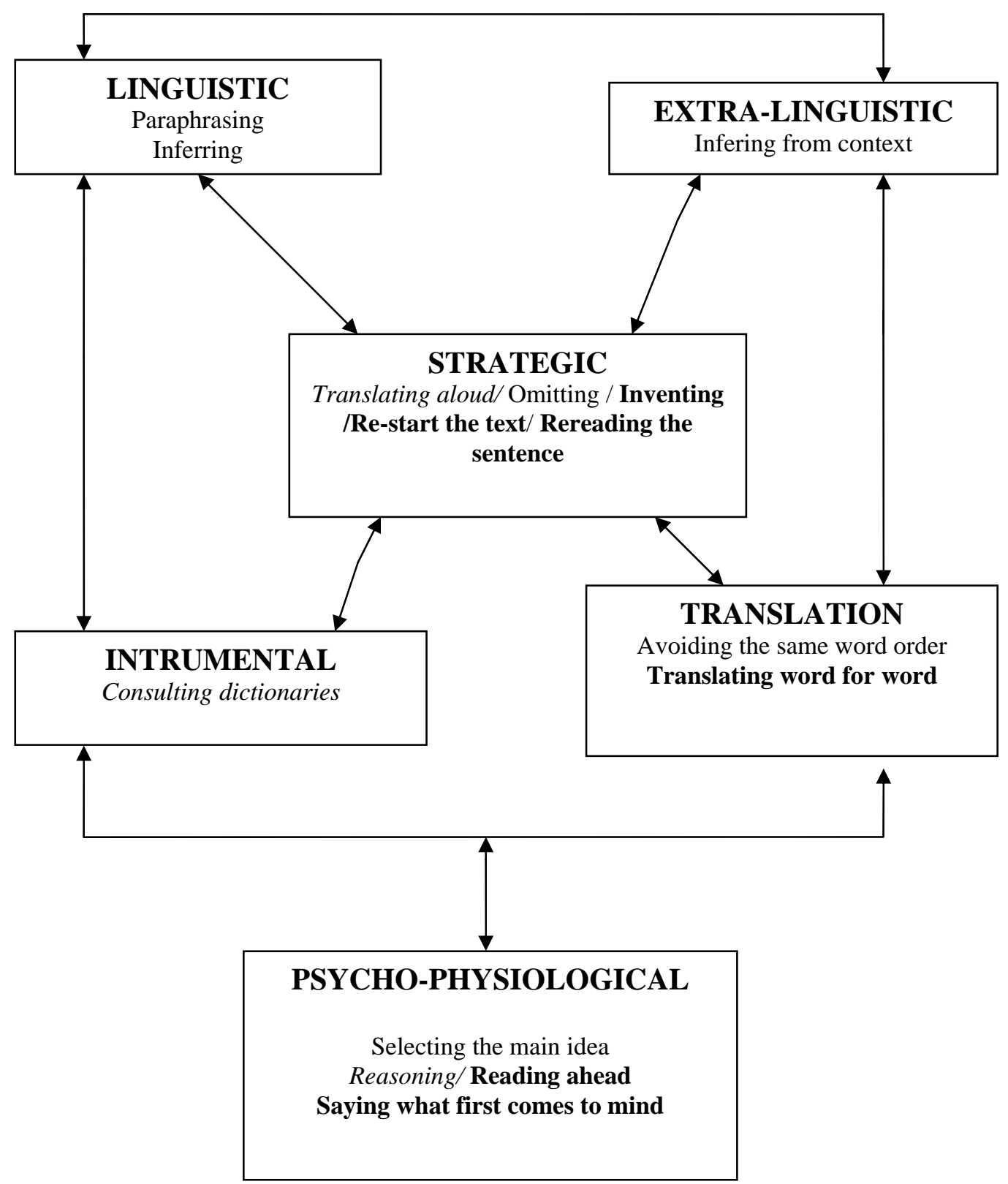

Fig. 11. Strategies used in both modalities: in regular font shared strategies, in italics specific strategies used in written translation, in bold specific strategies used insight translation(PACTE model: 2003)

As far as translation errors are concerned the high number of non-sens in ST is significant enough, 40 vs. 12 in WT (see figure 9). The cause of this type of error stems from either deficiencies in understanding of the source text or deficiencies in reexpressing the target text (linguistic, pragmatic, textual, etc.). Time constraints and lack of macroprocessing abilities probably hindered the correct output in ST. The sample disclosed many problems of comprehension which probably led to a large number of translation non-senses. The varied and numerous strategies were not effective probably due to the demanding efforts the ST modality requires and the fact that the 
sample was not made up of professional interpreters. On the other hand, the number of faux sens is only slightly higher in ST, and surprisingly enough there were more contresens in WT. Some subjects were able to solve satisfactorily a particular problem in ST but the same problem was not solved in WT. The only plausible explanation is that some unconscious and spontaneous strategy that worked well was applied but they were not able to apply the same strategy after giving it some thought.

As far as causes of translation problems is concerned quantitative differences are more obvious than qualitative differences in each modality. A frequency of 102 causes in ST, almost half of them (45) associated to psycho-physiological components. In WT 59 were found. Three specific sight translation causes and two WT. In the latter modality problems are distributed among all the subcompetencies.

\section{CONCLUSIONS}

Causes of problems and strategies were not difficult to fit within the PACTE translation competence model. This suggests that empirical data can be connected to this theoretical model and it has potential to explain translation competence in experimental settings. Experiments with larger samples made up of practicioners and/or practicioners vs. trainees of the different translation and interpreting modalities could improve our knowledge of translation competence and validate the model.

The higher number of translation errors made by the sample supports the assumption that sight interpreting as an interpreting modality is more demanding that written translation. Other experimental findings support the hypothesis that sight translation is even more demanding that other interpreting modes (Agrifoglio, 2004). This is consistent with the fact that a considerable number of causes of problems and strategies used in sight translation belong to the psycho-physiological components. This suggests that a wider range of them are required for sight translation compared to written translation. In other words, sight translation demands a deeper cognitive processing activity (efforts in Gile's terminology, Gile: 1995). It also supports the concept that sight translation is more of an interpreting modality than a hybrid modality. Psycho-physiological components should, therefore, be emphasized in sight translation training and sight translation included in interpreting training, as it is usually the case. 
As to the problems and strategies found in written translation, most of them are included in the knowledge about translation sub-competence -related to translation units, processes, deverbalization, reexpression etc. In the light of our results written translation competence is more concerned with a systematic knowledge of language transfer aiming at a more adequate target text. These concerns did hardly arise in the sight translation modality. It shows that written translation training should pay especial attention to this sub-competence. We wonder if this su-competence is not better mastered by professional translators than by professional interpreters.

The high number of strategies in both modes subsumed under the strategic subcompetence shows both the difficulties encountered by the subjects during the tasks and supports the theoretical importance the PACTE model grants to this sub-competence. It is in consistence with the assumption that the strategic sub-competence compensates for deficiencies in the other sub-competencies. Translation students should be made more aware of their existence and they should be taught how to apply them, especially in emergency cases. The relevance of the rest of the sub-competences was more or less similar between both modalities showing that linguistic, extralinguistic, and instrumental sub-competences are of equal importance for both modalities.

We are fully aware of the limitations of this study: mainly a small sample made up of students and the use of only one measuring method. A replication of this study should use additional measuring instruments to complement retrospection and perhaps subjects should be made more aware of the existence of translation strategies so that they could identify them more easily (no mention was made of some widely used strategies such as approximation, expansion, anticipation, waiting, compression, segmentation, morphosyntactic transformation, generalization, use of linguistic openend forms, etc.) which does not mean that the sample did not use them. Nevertheless, this study may serve as a pilot.

\section{CITED WORKS}

ABUIN, Marta. 2007. El proceso de interpretación consecutiva. Un estudio del binomio problema/estrategia. Granada: Comares.

AGRIFOLIO, Marjorie. (2003). El uso de la traducción a vista en la enseñanza de la interpretación. Tradução \& Comunicação. 12, 99-113. 
AGRIFOLIO, Marjorie. 2004. Sight Translation and Interpreting. A comparative analysis of constraints and failures. Interpreting, 6:1, 43-67

Curvers, P., Klein, J., Riva, N. \& Wuilmart, C. (1986). La traduction à vue comme exorcice préparatoire et complémentaire à l’interprétation de conférence. Cuadernos de Traducció e Interpretació no. 7, 97-116.

GERLOFF, Pamela. 1987: "Identifying the Unit of Analysis in Translation: Some Uses of Think-aloud Protocol Data", en FAERCH, Claus, Gabriele KASPER (eds.) Introspection in Second Language Research, Clevelong, Multilingual Matters: 5-23

GILE, Daniel. 1991. "Methodological Aspects of Interpretation and Translation Research" Target 3, 2:153-174

GILE, Daniel. 1995. Basic Concepts AND Models for Interpreters and Translators Training. Amsterdam- Philadelphia: Benjamins

HURTADO ALBIR, Amparo. 2001. Traducción y traductología. Madrid: Cátedra:

IVANOVA, A. (2000) The Use Of Retrospection in Research On Simultaneous Interpreting. IN S. TIRKONEN-CONDIT Y R. JÄÄSKELÄINEN, (eds). Tapping and Mapping the Processes of Translation and Interpreting Outlook on Empirical Research. Amsterdam/philadelphia: John Benjamins

KALINA, Silvia. 2000. “Interpreting Competences as a basis and a goal for teaching. Interpreters' Newsletter, 10. 3-32

JÄÄSKElÄINEN, Riita, Sonja TIRKKONEN-CONDIT. 1991. "Automatised Processes in Professiona vs. Non-professional Translation: a Think-aloud Protocol Study", en TIRKONNEN-CONDIT, Sonja. (ed.) Empirical Research in Translation and Intercultural Studies. Tubinga: Gunter Narr.

JimÉNEZ IVARS, Amparo. 2001. La traducción a la vista. Un análisis descriptivo. Castellón: Publicacions de la Universitat Jaume I

KRINGS, Hans Peter. 1986. Was in den Köpfen von Übersetzern vorgeht. Tübinga: Gunter Narr [What happens in the Minds of Translators]

KUSSMAUL, Paul. 1995. Training the translator. Amsterdam-Philadelphia: John Benjamins, 
LÖRSCHER, Wolfgang. 1991. Translation Performance, Translation Process, and Translation Strategies. A psycholinguistic investigation. Tübinga: Gunter Narr.

MARTIN, Ann. (1993). Teaching sight translation to future interpreters. In C. Picken (Ed.), Translation - the vital link. Proceedings of the 13th World Congress of FIT. Brighton, August 6-13, 1993, vol. 1. London: Institute of Translation and Interpreting, 398-405.

MeAD, P. (2000) Control of Pauses by Interpreters in their B and A languages. The Interpreters’ Newsletter, 10, 89-102

Moser-Mercer, Barbara. 1997. "Beyond curiosity. Can Interpreting Research Meet the Challenge?” En Danks; Joseph H. , Gregory M. Shreves, Stephen B. Fountain y Michael K McBEAth (eds.) Cognitive Processes in Translation and Interpreting. Thousand Oaks: Sage, 176-205:194

Orozco, Mariana; Amparo HuRTAdo AlBIR. 2002. "Measuring Translation Competence Acquisitioin”. Meta 47, 3, 375-402

PACTE. [BEEBy, ALLISON; FERNÁNDEZ RODRÍGUEZ; OLIVIA FOX, AMPARO HURTADO ALBIR, WILLIAM NEUNZIG, MARIANA OROZCO, PATRICIA RODRÍGUEZ INÉS, LUPE ROMERO (Principal Investigator: AMPARO HURTADO ALBIR)]. 2003. "Building a Translation Competence Model”. En Alves, F. Triangulating Translation: Perspectives in process Oriented Research. Amsterdam-Philadelphia: John Benjamins. 43-68

RICCARDI, Alessandra. 2005. "On the Evolution of Interpreting Strategies in Simultaneous Interpreting" META, 50, 753-767

Schjoldager, Anne. 1995. "An Exploratory Study of Translational Norms in Simultaneous Interpretating: Methodological Reflections", en JANSEN, Peter. Translation and the Manipulation of Discourse, Leuven: CETRA

VIK-TOUVINEN, G.V. (2000) The interpreters' comments in interpreting situations. In: S. Tirkonen-condit y R. Jääskeläinen, (eds). Tapping and Mapping the Processes of Translation and Interpreting Outlook on Empirical Research. Amsterdam/philadelphia: John Benjamins

VIEZZI, Mario. (1990). Sight translation, simultaneous interpretation and information retention. In L. Gran \& C. Taylor (Eds.), Aspects of applied and experimental research on conference interpretation. Udine: Campanotto, 54-60. 
WEBER, William. 1990. "The Importance of Sight Translation in an Interpreter Training Program", en BOWEN, David., Margaretta BOWEN, (eds.) Interpreting, Yesterday, Today and Tomorrow, ATA Scholarly Monograph Series IV, Amsterdam-Philadelphia: John Benjamins: 44-52

\section{APPENDIX}

\section{HOW AMERICA IS CHANGING}

The conference began with discussion of changes in American society. Several American participants noted that theirs is largely an inward-looking society, and though Americans like to be loved, in fact they do not generally act out of concern for their image abroad. On the other hand, international economic "competitiveness" has become a critical issue for the United States and has assumed a high political profile. Indeed, at least as of mid-1986, it is perhaps the leading issue of the nascent 1988 presidential campaign. And as one participant pointed out, it is important to understand that to many Americans "competitiveness" means "Japan".

That competitiveness, in turn, was seen by many to be adversely affected by at least two major interrelated social problems in the United States- the breakdown of the family and the inadecuacies of the American educational system. The collapse of the family not only reduces the nurturing so critical to an individual's attaining high educational levels, but it also raises social costs and lowers social benefit through its impact on a host of phenomena including literacy, teenage pregnancies, and crime. Although the United States has more Nobel laureates than any other nation, the failure of its educational system was seen in its ranking at the bottom of the 15 OECD countries in math and science (while Japan ranks first).

\section{RETROSPECTIVE QUESTIONNAIRE (both after the sight translation task and the written task).}

1. "What specific problems did you come across during the sight translation performance? What were the causes of those problems? State them whether you were able to solve them or not. You don't have to fill in every blank but add elements if necessary.

1.

2.

3.

4.

5.

6.

7.

8. 
9.

10.

2. State what you did to solve each of the above mentioned problems. 1 is for problem $1 ; 2$ is for problem 2, etc.

1.

2.

3.

4.

5.

6.

7.

8.

9.

10.

3. "How do you assess each of your solutions. Use the following criteria: 0: unacceptable solution. 1: Partially aceptable solution. 2. Aceptable solution"

Just write a number. Remember 1 is for problem 1; 2 is for problem 2, etc.

1.

2.

3.

4.

5.

6.

7.

8.

9.

10. 